\title{
From Bedside to Bench: Reverse Engineering Medical Progress
}

\author{
Jonathan D. Kaunitz
}

Published online: 15 September 2012

(C) Springer Science+Business Media, LLC (Outside the USA) 2012

The public expects that, over time, will come new medical advances that add years to our lives, help cure disease, and increase quality-of-life. Less understood is the idea that scientific progress in medicine requires several steps: fundamental discovery (Stage 1); translation of discoveries into clinical relevance (Stage 2); development of practical clinical interventions (Stage 3); and evaluation and refinement of an intervention into practice (Stage 4). All four steps are needed for medical progress to occur (Fig. 1). My thesis is that fundamental discovery is the most critical, since without it none of the other steps are possible. To illustrate this point, I have chosen to discuss the scientific basis of the development of histamine $\mathrm{H}_{2}$ receptor antagonists $\left(\mathrm{H}_{2} \mathrm{RAs}\right)$, which at the time of their clinical approval represented a major therapeutic advance for peptic ulcer disease.

To illustrate the history of the development of H2RAs, I have "reverse engineered" the current literature, borrowing a term from those who disassemble a finished product in order to uncover its beginnings. In this case, the origins of currently used therapies can be traced back in time by searching the historic literature. Although the origin of $\mathrm{H}_{2} \mathrm{RAs}$ can be traced back to the discovery of gastric acid secretion or to the dawn of organic chemistry, a valuable starting point is the early twentieth century with the initial description of histamine in bioactive tissue extracts [1]

J. D. Kaunitz ( $\square)$

Bldg 114, Room 217E, West Los Angeles VAMC,

Los Angeles, CA 90073, USA

e-mail: jdkaunitz@gmail.com

J. D. Kaunitz

David Geffen School of Medicine at UCLA, Los Angeles,

CA 90073, USA
(Stage 1). This was followed by Popielski's landmark studies in which parenteral histamine increased the rate of gastric acid secretion [2] (Stage 2). Next came the initial description of nonselective antihistamines in 1937 and their subsequent use [3]. The failure of these antihistamines to inhibit gastric acid secretion was reported in 1949 [4], leading to the discovery of the selective $\mathrm{H}_{2}$ RAs in 1966 [5]. From there, preclinical and clinical development followed (Stage 3), eventuating in the commercial release of cimetidine in the UK in 1976-some 65 years following the initial description of bioactive histamine in living tissue. After 1976, cimetidine and drugs in its class were subjected to large-scale clinical trials, cost/benefit analysis, meta-analysis, and other evaluations [6] (Stage 4) for the treatment of peptic ulcer, reflux esophagitis, and other acidrelated conditions. $\mathrm{H}_{2} \mathrm{RAs}$ represented the end of an era of ulcer therapy that had emphasized diets, psychotherapy, antacids, and surgery, eventuating in a steep decline in hospitalizations and surgery for peptic ulcer [7], a paradigm shift in the treatment of a then common and morbid disease.

The development of $\mathrm{H}_{2} \mathrm{RAs}$ illustrates the typical progression of medical science. Although in retrospect a straight line can be connected from the initial discovery to the eventual clinical treatment, there were plenty of dead ends along the way, slowing but not stopping progress as the alternative explanations were sorted out. This history also stresses the importance of original observations reported from small laboratories, studies driven primarily by curiosity rather than a need for practical application.

The historical basis for the development of $\mathrm{H}_{2} \mathrm{RAs}$ contrasts with many of the precepts that drive the funding of scientific research. Many current grant applications must contain a statement about the clinical applicability of the intended findings, with some agencies even imposing a 


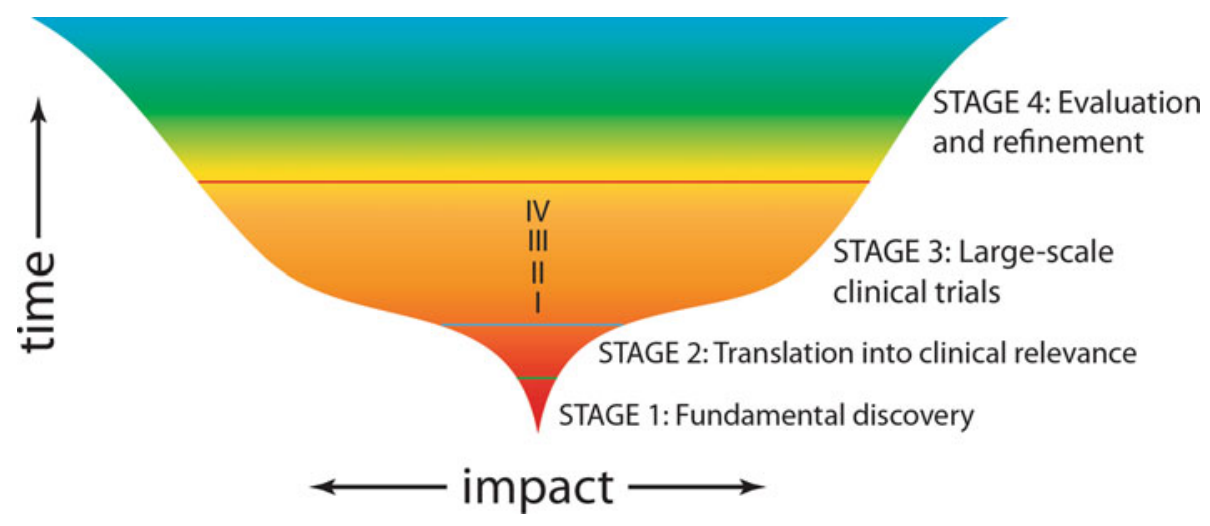

Fig. 1 Conceptual rendering of scientific medical progress. The development of new therapies is usually predicated on a single fundamental observation that, when confirmed by others and its importance realized, explodes into a new field of medical knowledge,

time frame for the medical relevance of the scientific discoveries that they fund. Certainly, history is full of examples of how a massive directed effort produced successful therapies for a given disease state: the major and rapid progress of drugs used to treat human immunodeficiency virus (HIV) serves as an excellent example of the benefits of a disease-directed approach. Delving more deeply, the rush to develop drugs used to treat HIV infection came at a time when a reasonable knowledge, based on pioneering fundamental research from the 1950s and 1960s regarding the mechanism of viral replication, was available. When applied to the modification of organic compounds with antiviral activity, rapid progress occurred. With this information in hand, developing drugs against a new and deadly virus was more a matter of targeting and refining therapy rather than making new fundamental discoveries. Thus, although targeting disease occupies a useful and valuable place in medical science, it can by no means supplant or replace the fundamental observations on which applied research is based. Furthermore, scientific progress is typically slow, with many decades spanning an initial discovery and a clinical intervention.

My fear is that the growing number of alternatives to a career in fundamental research will thin the ranks of clinician-investigators to the point that scientific progress will slow. Although fundamental research is but one stage of scientific progress, it is currently among the most difficult and frustrating due to declining federal funding, the need for extensive training in laboratory techniques, burdensome regulations, and the frustration associated with delayed gratification and uncertain success. The new generation, with its technology-driven need for instant gratification, is less likely to enter into this risky, arduous, and potentially aggravating field. The danger of losing curiosity-driven basic research is that science cannot progress without it. No that then goes through steps of translation into clinical relevance, progressively larger scale clinical development, and finally evaluation and refinement when in large-scale use

amount of secondary data analysis can compensate for the lack of new insights into how the body works. If, for example, fundamental discovery in the field of ulcer research had stopped in 1900, science would not be aware of gastrin, the neural control of acid secretion, $\mathrm{H}_{2} \mathrm{RAs}$, proton-pump inhibitors, or Helicobacter pylori. Ulcers would still be diagnosed radiologically and might be treated with arsenic or strontium gastric douches, intragastric electrodes, hot baths, and other interventions that were as toxic and painful as they were ineffective [8]. The situation in 1900, however, was unbalanced in that most scientific progress was in the realm of basic discovery, with clinical therapies based directly on the results of animal studies or on prior anecdotal clinical experience. Rigorous, structured testing of therapies for safety and efficacy was not systematized until the 1930s, and only recently reached its current form of thorough safety and effectiveness testing. Furthermore, systematic evaluation and refinement of therapies in practice was essentially unknown. Thus, the considerable progress in the fundamental understanding of disease mechanisms contrasted with woefully inadequate testing and regulation of therapies, resulting in the unfettered proliferation of dangerous and ineffective treatments. In 2012, Stage 3 and Stage 4 science has burgeoned, with resultant unprecedented refinement of the use of existing therapies, ensuring the safety, efficacy, and optimal utilization of most interventions. The problem is that inordinate emphasis on latter-stage science, due to its importance and attractiveness, threatens to draw off young investigators away from early-stage research.

Since the nature of fundamental research cannot be altered, and nor can the mores of our current generation of trainees be changed, it is incumbent on the senior academics to encourage the next generation into pursuing careers in basic research. Nothing can replace the thrill of 
making an original scientific discovery, uncovering something known previously only to the natural world, resulting in a feeling akin to being the first to climb a mountain or to descend to the ocean's depths.

For its part, the National Institutes of Health has admirably incentivized young investigators with higher priority scores, while continuing to fund top-class fundamental scientific investigation. This has been hampered, however, by flat funding and declining paylines, which has seriously eroded the funding of meritorious grant applications. This, combined with the increasingly burdensome regulation of research, has further de-incentivized young investigators from pursuing careers in early stage investigation. Our affiliated society, the Gastrointestinal Research Group (GRG), has re-organized to promote young investigators through recognizing outstanding research in this cohort. Although Digestive Diseases and Sciences (DDS) is not in the business of sponsoring research, it is entirely within its scope to support these young investigators by publishing their meritorious work, inviting them to join our Editorial Board, and encouraging them to submit scientific reviews in their areas of expertise. Furthermore, I am starting a new publication category, "DDS New Digestive Science," which is aimed at promoting Stage 1 science by publishing manuscripts of particular note due to their originality, innovation, and potential impact on the field. This publication type will likely be highlighted as milestones in the discovery of future medical advances. "DDS New Digestive Science" will complement "Medical Education and Practice," a category already established to promote Stage 4 science.
We at $D D S$ hope that, through joint and coherent efforts of funding agencies, training programs, and journals, the importance and allure of fundamental investigation can be impressed on current and future generations of trainees. I invite your comments, but most of all the submission of your excellent work to our journal.

Acknowledgments I would like to thank the Department of Veterans Affairs and the NIH for their ongoing research support, and Professors Roy Orlando and Jay Pasricha and Ms. Genevieve Kaunitz for their helpful suggestions.

\section{References}

1. Barger G, Dale HH. $\beta$-Iminazolylethylamine a depressor constituent of intestinal mucosa. J Physiol. 1911;41:499-503.

2. Popielski L. $\beta$-imidazolyläthylamin und die Organextrakte. Pflügers Arch Ges Physiol. 1920;178:214-220.

3. Bovet D, Staub A-M. Action protectrice des éthers phénoliques an cours de l'intoxication histaminique. CR Soc Biol (Paris). 1937; 124:547-549.

4. Ashford CA, Heller H, Smart GA. The effect of antihistamine substances on gastric secretion in man. Br J Pharmacol Chemother. 1949;4:157-161.

5. Ash ASF, Schild HO. Receptors mediating some actions of histamine. Br J Pharmacol Chemother. 1966;27:427-439.

6. Deakins $\mathrm{M}$, Williams JG. $\mathrm{H}_{2}$-receptor antagonists in peptic ulcer disease. Efficacy in healing peptic ulcers. Drugs. 1992;44: 709-719.

7. Hermansson M, Ekedahl A, Ranstam J, Zilling T. Decreasing incidence of peptic ulcer complications after the introduction of the proton pump inhibitors, a study of the Swedish population from 1974-2002. BMC Gastroenterol. 2009;9:25.

8. Hemmeter JC. Diseases of the stomach. Philadelphia: Blakiston; 1897:17-788. 